\title{
Marcas discursivas de la diversidad. Acerca del lenguaje inclusivo y la educación lingüística: aproximaciones al caso argentino'
}

\author{
Discursive Marks of Diversity.About Inclusive Language and Linguistic \\ Education:Approaches to the Argentinean Case
}

\author{
CAROLINATOSI \\ Universidad de Buenos Aires- CONICET \\ Argentina \\ carolinaltosi@gmail.com
}

(Recibido: 23-O4-2OI9; aceptado: o7-05-2019)

Resumen. Si bien los movimientos que cuestionan el carácter sexista del español surgieron hace varias décadas, en la Argentina el tema tomó amplia notoriedad y ocupó el centro de los debates en los medios y redes sociales durante 2018. En efecto, a partir de ese año, comenzó a difundirse el uso del morfema -e como nueva marca de género que objeta el paradigma patriarcal y el binarismo.Atento a ello, en el presente artículo, abordo las diferentes formas del lenguaje inclusivo e indago su circulación en el ámbito educativo, específicamente en el ámbito de la enseñanza terciaria. Primero, señalo los diferentes recursos del lenguaje inclusivo y los caracterizo como marcas discursivas de la diversidad y huellas de disenso que ponen en escena las identidades genéricas invisibilizadas. Luego, muestro la relevancia del lenguaje inclusivo como objeto de análisis, en pos de una educación lingüística que fomente la pluralidad y el pensamiento crítico. Para ello, analizo algunas prácticas discursivas de lectura y escritura en instituciones educativas. Finalmente, hago foco en que el lenguaje inclusivo pone en juego cuestiones relacionadas con la identidad, la ideología, las normas y la corrección. Su tratamiento en las clases puede abrir espacios de debate y discusión e incidir en la profundización de la reflexión lingüística y el respeto por la diversidad.

Palabras clave: lenguaje inclusivo o no sexista; género;sexismo;educación lingüística;Argentina.
Abstract. Although movements questioning the sexist character of the Spanish language emerged several decades ago, in Argentina the theme gained wide notoriety and occupied the center of debates in the media and social networks during 2018. Indeed, since that year, the use of the morpheme -e as a new gender brand, that objects to the patriarchal paradigm and binary gender roles, began to circulate. Attentive to this, the present article approaches the different forms of inclusive language and its circulation in the educational field, specifically in the field of higher education in Argentina. First, this paper points out the different forms of inclusive language and characterizes them as discursive marks of diversity and traces of dissent that staged invisible generic identities. Then, it shows the relevance of inclusive language as an object of analysis, in pursuit of a linguistic education that encourages plurality and critical thinking. For this, some discursive practices of reading and writing in educational institutions are examined. Finally, there is a focus on the fact that inclusive language brings into play issues related to identity, ideology, norms and correction. Its treatment in the classes can open spaces for debate and discussion, and influence the deepening of linguistic reflection, and respect for diversity.

Keywords: Inclusive language or sexist; gender; sexism; language education;Argentina.

\footnotetext{
${ }^{\text {I }}$ Para citar este artículo: Tosi, C. (2019). Marcas discursivas de la diversidad. Acerca del lenguaje no sexista y la educación lingüística: aproximaciones al caso argentino. Alabe 20. [www.revistaalabe.com]

DOI: IO.I5645/Alabe2OI9.20.II
} 
En la lengua se libran todas las batallas.

María Teresa Andruetto

\section{Introducción ${ }^{2}$}

Los movimientos que cuestionan el carácter sexista del español surgieron hace varias décadas: comenzaron con los reclamos feministas, se cimentaron a través de los estudios de género y de la lucha del colectivo LGBTTTIQ+3 y plasmaron sus propuestas en cuantiosas guías de lenguaje inclusivo. No obstante, el debate sobre el uso del lenguaje inclusivo se instaló con fuerza en los últimos años.

En lo que se refiere específicamente a la Argentina, el tema comenzó a instalarse a partir de las acciones de "Ni una menos" - colectivo femenino contra la violencia machista formado en 2OI5-, aunque tomó amplia notoriedad y ocupó el centro de los debates en los medios y las redes sociales durante 20I8, a raíz del tratamiento del Proyecto de Ley de Interrupción Voluntaria del Embarazo ${ }^{4}$. En los discursos militantes a favor del aborto legal, seguro y gratuito -en su mayoría, provenientes de los sectores más jóvenes- emergió el uso del morfema -e como nueva marca de género que pone en cuestión el sistema binario. Por ejemplo, Natalia Mira, la vicepresidenta del Centro de Estudiantes del Colegio Nacional Carlos Pellegrini de la Ciudad de Buenos Aires, en un programa periodístico, opinó: "Hay poques diputades que están indecises, y queremos demostrarles que a nosotres no nos va a pasar por al lado que decidan que sigan muriendo mujeres o decidan frenar eso y legalizar el aborto" ( (12/6/2OI8).

\footnotetext{
${ }^{2}$ Agradezco a Osvaldo Osorio y Aimé Esteban por haberme permitido incorporar materiales didácticos y producciones realizadas en sus clases. Además, les doy las gracias, por un lado, a Verónica Sukaczer, quien me aportó datos sobre la relación entrẹ lenguaje inclusivo y discapacidad y, por el otro, a Aimé Esteban y Agustina Sabich por los comentarios y sugerencias que enriquecieron este trabajo. Finalmente, destaco la relevancia del Observatorio Latinoamericano de Glotopolítica del PELCC-UNTREF, coordinado por Diego Bentivegna y Daniela Lauría, por constituirse en un espacio de difusión y debate sobre cuestiones lingüísticas, que me aportó rico material de consulta.

${ }^{3}$ Con respecto a la sigla LGBTTTIQ+, se aclara que su significado remite a L, lesbianas; $\mathrm{G}$, gay; B, bisexual; $\mathrm{T}$, transgénero; $T$, transexual; T, travesti; I, intersexual; $Q$, queer y el + refiere a otras identidades, como pansexualidad, demisexual, asexual y antrosexual.

${ }^{4}$ En la Argentina, durante 2or8, se trató el Proyecto de Ley de Interrupción Voluntaria del Embarazo, que implicaba el derecho al aborto legal, seguro y gratuito. Este proyecto alcanzó la media sanción en la Cámara de Diputados pero fue rechazada en la Cámara de Senadores. Cabe aclarar que el proyecto recién se debatió en la octava vez que se presentó. Actualmente, la interrupción voluntaria del embarazo es ilegal y sigue muriendo gran cantidad de mujeres en abortos precarios. En 20I9, se presentó un nuevo proyecto.
} 
El fenómeno del lenguaje inclusivo provocó las más variadas reacciones en la sociedad: desde empatía y adhesión, hasta rechazo, burlas y actitudes agresivas y virulentas. Incluso, las personas que se expresaban de ese modo fueron tildadas de "ridículas", "deformadoras del lenguaje" y hasta de "ignorantes". Asociándolas a una mera moda adolescente, los medios y las redes sociales se encargaron de ridiculizarlas y parodiarlas.

Sin embargo, y como bien se sabe, el uso del morfema -e es uno de los tantos recursos de los que ofrece el lenguaje inclusivo. Además, es posible mencionar el empleo de la x y el @ - estos en los discursos escritos-, paráfrasis y sustantivos abstractos, entre otros.

A pesar de que los opositores al movimiento del lenguaje inclusivo lo desestiman y de que la Real Academia Española (de ahora en más, RAE) penaliza su uso, las formas inclusivas del lenguaje circulan con ímpetu en variados géneros y ámbitos: periodísticos, políticos, administrativos, artísticos, educativos, etc. Respecto de su empleo en las instituciones educativas, en ocasiones emergen de las voces del alumnado, a veces de la planta docente, y en otras en textos o discursos sociales que provocan el debate en el aula. Actualmente, existe una gran controversia sobre cómo tratar el tema en las instituciones de enseñanza. El llamado "lenguaje inclusivo" ¿puede ser contenido curricular?, ¿es solo una moda pasajera?, ¿atenta contra la gramática del castellano?, ¿el estudiantado puede hablar y escribir en lenguaje inclusivo?, ¿qué actitud toman, en esos casos, los y las docentes? Sin dudas, diferentes dimensiones convergen y provocan tensiones: la normativa y la trasgresión, la uniformidad y la diversidad, la corrección y la visibilidad de lo "otro", de lo "diferente", de lo que hasta ahora no había sido nombrado.

A partir de este encuadre, en el presente trabajo, me propongo abordar el movimiento del lenguaje inclusivo y, desde la perspectiva del Análisis del Discurso, caracterizo las formas del lenguaje inclusivo como huellas de la diversidad históricamente soslayada, que generan determinados efectos de sentido (Tosi, 20I8). Tal como explica Orlandi (2003: 63), el discurso se define por su materialidad simbólica y por los efectos de sentido (Pêcheux, I975 [1988]) producidos entre los interlocutores. Desde tal perspectiva, los efectos de sentido se producen en la inscripción de la lengua en la historia y se rigen por mecanismos ideológicos. Sin dudas, el lenguaje no impide situaciones de desigualdad y de discriminación, pero construye imaginarios y estereotipos que pueden fomentarlas.

En este artículo me centraré en abordar el lenguaje inclusivo de género como aquel que objeta el androcentrismo y la construcción binaria en el lenguaje. No obstante, algunos especialistas diferencian el lenguaje no sexista, que aboga por la visibilidad de la mujer -por ejemplo con el uso de la barra: maestro/a- del lenguaje inclusivo que apela a mostrar la diversidad de géneros y a oponerse binarismo establecido por el género gramatical -mediante el uso de lax, @ o e-. De esta diferenciación, también hablaré a lo largo del artículo. Por otra parte, hay que dejar en claro que el lenguaje inclusivo en términos generales puede implicar también el uso de términos que respetan una perspectiva de derechos y evita formas discriminatorias para referirse a diferentes grupos en situación de 
vulnerabilidad -no solo en lo que se refiere a cuestiones de género- como las "personas con discapacidad", las "personas adultas mayores", los "pueblos originarios", etcétera5.

En lo que sigue, primero, indago los vínculos entre lenguaje, ideología y género; luego, me ocupo de caracterizar el lenguaje no sexista, sus recursos y alcances y, posteriormente, planteo su abordaje en el aula.

\section{Lenguaje e ideología}

Por una lado, si hacemos referencia a la teoría de Pêcheux (I975 [ı988] y I983), el sujeto y el sentido son producidos históricamente y determinados a partir de las formaciones ideológicas de un grupo social dado. El sujeto no se encuentra en la base del sentido ni lo produce, sino que sujeto y sentido se interrelacionan para confluir en un determinado efecto de significación. Sobre esta base teórica, Pêcheux (I975 [I988] y I983) propone el concepto de formación discursiva, que es el espacio de constitución del sujeto y del sentido. Así, en una formación ideológica, la formación discursiva, que se da a partir de una coyuntura sociopolítica, establece qué es lo que se puede o se debe decir, y lo que no. Se considera, así, que las formaciones discursivas determinan formas de comportamiento y uso del lenguaje y, por ende, los sujetos se encuentran atravesados por la ideología del momento histórico en que se sitúan. Me parece importante referir a este enfoque, porque nos permite reflexionar sobre la idea de que el sujeto puede hacer elecciones sobre su discurso, pero siempre condicionado por el interdiscurso, que se relaciona con el universo de lo decible dentro de una formación ideológica. De este modo, determinadas formaciones discursivas - con base patriarcal- han contribuido a la circulación de ciertas formulaciones y a la consolidación de estereotipos en relación con los géneros. Por ejemplo, los refranes, frases populares y dichos cotidianos -que han sido analizados por diversos investigadores desde los más variados marcos teóricos-, vehiculizan imaginarios cristalizados sobre los géneros ${ }^{6}$, según vemos en los siguientes casos:

I) Dirigidas a una mujer: ¡Tenías que ser mujer!, jDebés estar indispuesta! (ambas ante alguna situación juzgada como negativa; en España, está ultima puede

\footnotetext{
5 Para mayor información sobre lenguaje inclusivo, consultar en la página web del Instituto Nacional contra la Discriminación, la Xenofobia y el Racismo de la Argentina: https://www.argentina.gob.ar/inadi.

${ }^{6}$ En este artículo, tomo la diferenciación entre sexo y género según la conceptualización del INADI. Por un lado, el sexo se refiere a la clasificación binaria entre varón y mujer. Una clasificación que hoy está relativizada en la medida en que se reconoce que los aspectos que constituyen el sexo biológico y anatómico de un ser vivo (cromosomas, hormonas, gónadas, estructuras sexuales internas y genitalidad) se dan de un modo diverso, y, por otra parte, se perciben según categorías culturales. Por el otro, el género implica un sistema de normas que determina cómo deben comportarse un varón y una mujer para ser percibidos como individuos diferenciados, según el sexo asignado al nacer. Esto incluye los roles, las costumbres, la vestimenta y el lenguaje a través de los cuales se representa la masculinidad y la feminidad en una determinada cultura. Por su condicion social y cultural, las atribuciones del género son variables de acuerdo con el contexto histórico. Las representaciones y valoraciones de lo femenino y lo masculino -y las normas que regulan sus comportamientos y las atribuciones de cada sexo- son producto de construcciones sociales y culturales. Finalmente, se aclara que la identidad de género se concibe como la percepción que una persona tiene de su propio género y de sí misma, más allá del sexo biológico que le haya sido asignado el momento de nacer (Fuente: Inadi, https:// www.argentina.gob.ar/inadi).
} 
escucharse de este modo: ¡Debes estar con la regla!), jPortate como una señorita!, Sos una muñequita, Sos rapidita (en referencia a tener relaciones sexuales).

2) Dirigidas a un varón: No llores como una nena o No llores, no seas maricón, Comportate como un hombre; Sos un campeón; Sos un ganador (en referencia a "triunfos" sexuales).

3) Refranes y dichos: Detrás de un hombre hay una gran mujer, Es una mujer fácil (nunca un hombre es "fácil”), Si la vaca fuera honrada, no tendría cuernos el toro.

Como es evidente, la fragilidad, el malhumor, la inoperancia, la obligación de tener buenos modales y ser "decente", entre otros rasgos, son asignados al género femenino. En tanto que la fortaleza, la habilidad y la relevancia social, entre otras cualidades, son atribuidas al género masculino. Estos ejemplos muestran los aspectos que tradicionalmente han sido asignados a cada uno de los géneros, cuáles son los comportamientos que se espera de la mujer y del hombre y qué rasgos los definen y configuran.

En segundo lugar y para consignar un ejemplo reciente, a continuación se observa una campaña gráfica por el "Día del Niño" realizada por un hipermercado en 20 o en la Argentina. Los carteles anunciaban: C de campeón y C de cocinera (imagen I); C de constructor y $\mathrm{C}$ de coqueta (imagen 2 ).

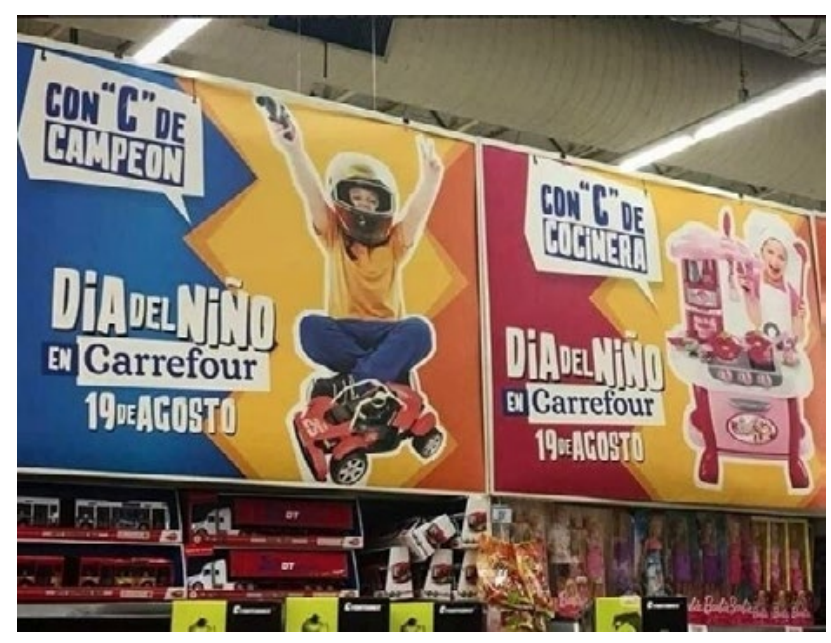

(1). Campaña publicitaria

Día del Niño. Carrefour.

Argentina, 2018.

(2). Campaña publicitaria Día del Niño. Carrefour.

Argentina, 2018.

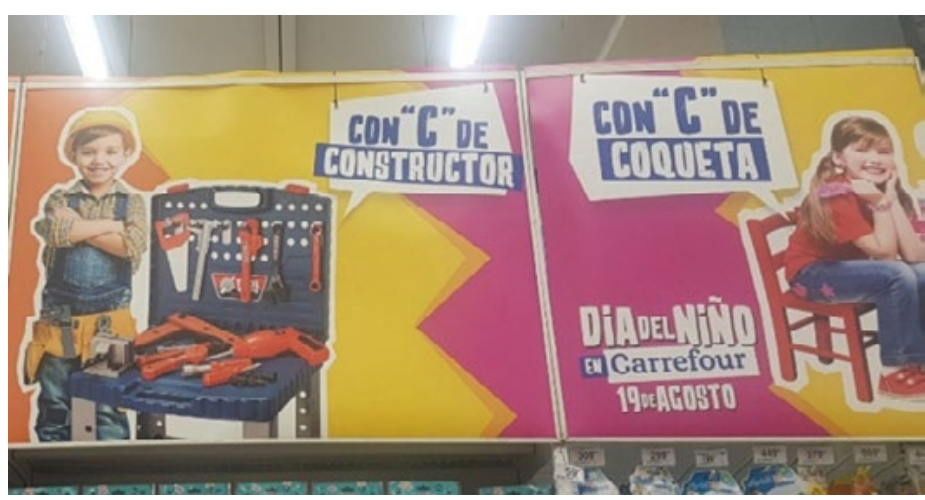


Como se observa, la publicidad reduce el género femenino al rasgo de coquetería o a la acción de cocinar, mientras que el varón es campeón y constructor. A raíz de las críticas en los medios y las redes sociales, el hipermercado admitió que la campaña reproducía los estereotipos de género y tuvo que retirar los afiches.

Por otro lado, en referencia a los estudios de género, algunas investigaciones plantean que, en esta nueva coyuntura, los cambios sobre los discursos pueden influir en los comportamientos y en las percepciones sociales (Butler, I990). Es decir, que el hecho de que se objeten los roles o rasgos tradicionalmente asignados a la mujer y al hombre ya es un gran avance en las representaciones de género, porque se comienzan a cuestionarlos y desnaturalizarlos. Así, mediante el lenguaje se configuran subjetividades, se vehiculizan concepciones ideológicas, cimentando "realidades" y excluyendo otras.

El lenguaje actúa sobre los imaginarios y, por ello, intervenir sobre los discursos sexistas puede propiciar el cuestionamiento de ciertos comportamientos que van más allá del lenguaje. En este sentido, "No es la lengua que sea sexista, sino que hay discursos que lo son” (García Negroni, en Zabala, 20I8). Entonces, ¿es posible lograr un lenguaje inclusivo? A continuación, indago esas cuestiones.

\section{Hacia un lenguaje inclusivo}

Cabe tener presente que, en los 9o, los estudios de Judith Butler propiciaron la idea de que el lenguaje constituye un factor determinante en la construcción del género. Desde esa perspectiva, puede considerarse que el lenguaje actúa sobre las percepciones sociales y, por ello, es necesario intervenirlo, con el fin de lograr la visibilización de la mujer y mostrar una apertura hacia la diversidad de género.

Respecto del caso español, se ponen en diálogo dos tipos de género: el gramatical y el social. Según explica Ramírez Gelbes (20ı9, en línea):

el género gramatical corresponde a ciertas clases de palabras (el sustantivo, el pronombre) y en español puede ser femenino o masculino. Por esa misma dualidad, cuando el género gramatical alude a seres sexuados, los ubica en una categoría binaria. El género social, por su parte, se refiere a la categoría sociocultural que se relaciona con las identidades y los comportamientos de los sujetos. Suele asociárselo con los estereotipos.

Ya en 1995, Carmen Alario, Mercedes Bengoechea, Elira Llendó y Ana Vargas, integrantes de la Comisión Asesora sobre el Lenguaje del Instituto de la Mujer, de Madrid, sostenían que el uso del masculino genérico "se basa en un pensamiento androcéntrico que considera a los hombres como sujetos de referencia y a las mujeres seres dependientes" (เ995: 4). En la actualidad el género social objeta no solo el androcentrismo lingüístico, sino también el binarismo dado por la gramática. En efecto,

Como muchas otras lenguas, el español es androcéntrico. Fueron hombres quienes hicieron las gramáticas y desarrollaron los diccionarios. Fueron hombres quienes tuvieron el poder para 
establecer las políticas públicas relacionadas con la lengua. Fue su expresión la que quedó cristalizada como abarcadora. La cuestión es que el género social de nuestro tiempo ya no acepta el androcentrismo lingüístico tradicional. $\mathrm{O}$ no acepta la estereotipia binaria que el género gramatical le impone. Entonces, ni el masculino genérico ni el femenino a secas interpelan a la generalidad (Ramírez Gelbes, 2org: en línea).

Recordemos que, según la gramática de la RAE, cuando se hace referencia a sustantivos que designan seres animados, el masculino designa la clase que corresponde a todos los individuos, sin distinción de sexos. Por ejemplo, en la frase "Los maestros reclaman mejoras en sus salarios" se estaría incluyendo tanto a hombres como a mujeres. Por eso, se dice que el masculino es un género no marcado, ya que alude al miembro de una oposición binaria que puede abarcarla en su conjunto, lo que hace innecesario mencionar el término marcado -el femenino-.

Por el contrario, los movimientos que abogan por el lenguaje inclusivo sostienen que el uso del masculino genérico produce ambigüedades y confusiones. Por ejemplo, en el caso anterior se estaría ocultando a "las maestras". Entonces, y a partir del postulado de que la utilización del masculino para referirse a los dos sexos no consigue visualizar a la mujer, y que esto deviene de "la falta de representación simbólica de las mujeres en la lengua" (Alario, Bengoechea, Llendó y Vargas, I995:4), diversas guías -especialmente a partir del año 200O- propusieron formas alternativas para tender a un lenguaje no sexista, como el desdoblamiento o doble mención ("maestros y maestras"), la paráfrasis y el reemplazo por sustantivos abstractos ("quienes estudian" o "el estudiantado" por "los estudiantes"), uso de femenino en las profesiones (intendenta) así como el uso de barras ("los/as compañero/as"), el arroba (1@s compañer@s) y lax ("lxs compañerxs") en los textos escritos. A ellos, como ya adelanté en la introducción, se sumó el uso de la -e ("maestres").

La postura de la RAE resulta categórica: desestima los usos del lenguaje inclusivo por agramaticales en el caso del @, laxy-e, o por artificiosos e innecesarios respecto de los desdoblamientos, las paráfrasis o los sustantivos abstractos. Sin dudas, para la RAE, el lenguaje inclusivo atenta contra el uso "legítimo" o "correcto" de la lengua. Pero como bien se sabe, las academias no pueden dominar el uso de la lengua, y las formas lingüísticas no sexistas e inclusivas se imponen y circulan. Aparecen principalmente en intercambios orales y en ciertos géneros escritos de las nuevas tecnologías, de índole informal, como en las redes sociales?. Veremos algunos ejemplos a continuación.

\footnotetext{
${ }^{7}$ Llegados a este punto cabe mencionar que existen diversos materiales que tratan los procesos de lectura y escritura en los géneros de Internet. Entre ellos,se destaca diccionario Nuevas formas de leer. Diccionario de conceptos clave de lectura y escritura, que aborda los nuevos fenómenos de lectura y escritura en relación con los actuales paradigmas científicos de las Humanidades, las Ciencias Sociales, las Tecnologías de la Información y la Comunicación, la Biología y la Ecología, etc. Si se desea ampliar el tema, consultar Martos, E. y Campos, M (2OI2).
} 


\section{I. Barras y $x$}

Por su rasgo de mayor formalidad, el empleo de la barra prevalece en los textos administrativos o instructivos, como vemos en las directrices de presentación de originales de una revista académica: "los/as autores/as" (cf. 3). En cambio, en las redes sociales y diversos géneros digitales que se caracterizan por una mayor informalidad, predomina el uso de la x: "lxs compañerxs desaparecidxs y asesinadxs" (cf. 4). Puede observarse, así, que hay ciertos usos del lenguaje inclusivo ligados al género discursivo en el que se inscriben los textos.

(3) La evaluación de los trabajos estará a cargo de árbitros externos/as y anónimos/as. La identidad del/la autor/a también se mantendrá en reserva durante el proceso de evaluación. Los/as autores/as serán notificados de la aceptación o rechazo del manuscrito. Asimismo, se podrá devolver el texto para incorporar las modificaciones aconsejadas por los/as evaluadores/as dentro de los plazos convenidos por el Comité Editorial. En “Directrices para autores/as”, en Revista Exlibris. Publicación anual del Departamento de Letras de la Facultad de Filosofía y Letras de la Universidad de Buenos Aires.

(4) Anuncio de la Comisión El Vesubio y Puente 12 sobre un acto homenaje a los desaparecidos y asesinados en la última dictadura cívico-militar argentina.

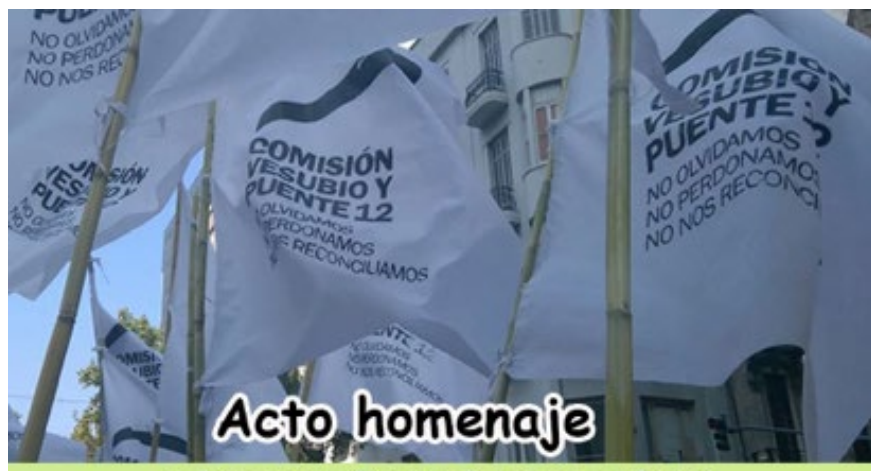

a Ixs compañerxs desaparecidxs y asesinadxs de los campos de concentración El Vesubio, Puente 12, Comisaría de Monte Grande, La 205 y a lxs 30.000

Jueves 20 de septiembre de 2018 - 18:30hs Av. Belgrano 2527 - CABA - Auditorio ATE

La limitación de ambos recursos es que solo pueden usarse con eficacia en textos escritos, pues oralizar la inclusión de la barra es una tarea por demás ardua y la x es impronunciable. Además, tanto la x como el @ - este último recurso actualmente se halla en desuso- no pueden ser reconocidos por los dispositivos lectores que emplean las personas con discapacidad visual. 


\subsection{Desdoblamientos}

En relación con los desdoblamientos, en primer lugar, me referiré a un caso muy significativo que ilustra el fenómeno de modo contundente. Se trata de una ilustración que en 2019 el dibujante e historietista Miguel Repiso (Rep) subió a su muro de la red social Facebook en el Día Nacional de la Memoria por la Verdad y la Justicia, que se conmemora en la Argentina cada 24 de marzo ${ }^{8}$.

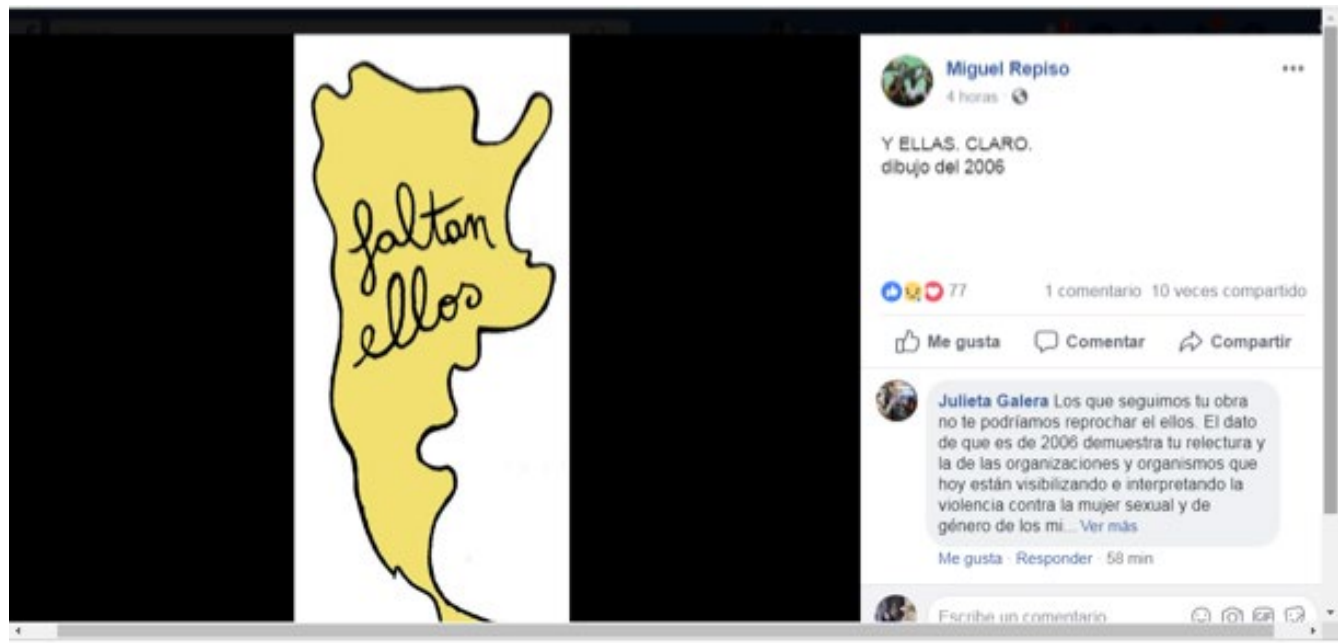

(5) Muro de Miguel Repiso (Rep), 24/3/2019.

Como se observa en (5), la publicación alude a los desaparecidos en la última dictadura cívico-militar. Si bien la leyenda sobre el mapa argentino señala: "Faltan ellos", Rep añade la siguiente descripción: "Y ellas, claro. Dibujo del 2006". Sin dudas, el desdoblamiento que figura en la aclaración ("y ellas") vehiculiza la necesidad de visibilización del género femenino en un nuevo contexto social. La reformulación realizada por el enunciador mediante la explicitación del pronombre femenino consiste en una operación discusiva que evidencia que, en este nuevo contexto (trece años después), el masculino genérico se muestra como insuficiente y poco representativo. Entonces, el masculino con pretensiones genéricas ya no alcanza y "las desaparecidas" deben ser nombradas a través de la explicitación del pronombre femenino en plural. Llegados a este punto, traigo a colación un fragmento del discurso de cierre al Congreso de la Lengua Española de 20I9, que pronunció la escritora María Teresa Andruetto y que remarca la idea de que el lenguaje hace visibles los patrones de comportamiento social y ciertos valores que antes estaban silenciados:

\footnotetext{
${ }^{8}$ En la Argentina, el Día Nacional de la Memoria por la Verdad y Justicia es una fecha en la que se conmemora y busca mantener vivos en la reflexión y memoria social los tristes acontecimientos producidos en la última dictadura cívico-militar, entre ellos, la desaparición de 30.000 personas y la apropiación de más de 5 Oo niños y niñas. Información extraída de la página web del Inadi.
} 
En la lengua se libran batallas, se disputan sentidos, se consolida lo ganado y los nuevos modos de nombrar -estos que aparecen con tanta virulencia- vuelven visibles los patrones de comportamiento social. Palabras o expresiones que llegan para decir algo nuevo o para decir de otro modo algo viejo, porque el lenguaje no es neutro, refleja la sociedad de la que formamos parte y se defiende marcando, haciendo evidente que los valores de unos (rasgos de clase o geográficos o de género o de edad...) no son los valores de todos. (Discurso de clausura del Congreso Internacional de la Lengua Española, 30/3/2019).

Por otro lado, en (6) muestro un desdoblamiento en un texto pedagógico: "niños y niñas". Si bien el uso de la doble mención no suele figurar en las hojas de estilo de las editoriales comerciales, es muy frecuente encontrar este tipo de recurso -y cada vez en mayor cantidad--.

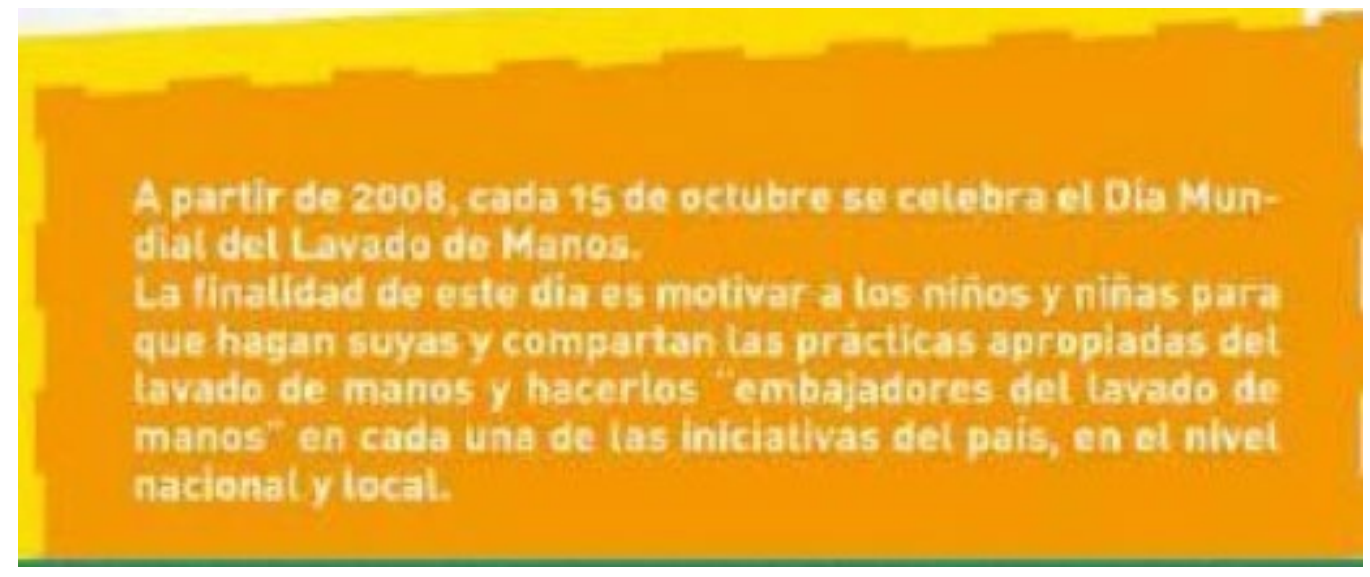

(6) Fragmento de un fascículo de un coleccionable de la editorial Penguin Random House.

Sin embargo, hay dos cuestionamientos que se suelen hace sobre las dobles menciones. Uno el que consigna la RAE, acerca de que son innecesarios (Bosque, 2OI2). Pero como ya expliqué, en muchos contextos la visibilización de la mujer se manifiesta imprescindible en determinadas situaciones de enunciación. Otro de los cuestionamientos consiste en que se los suele percibir como obstáculos para una lectura fluida. Por ello, en muchas ocasiones suele aplicarse el desdoblamiento al inicio del texto y luego se prosigue con el masculino genérico -en detrimento de una coherencia u homologación discursiva-. Esto es lo que sucede en (6), luego del desdoblamiento rige el masculino genérico; no se lee: "hacerlos y hacerlas embajadores y embajadoras", sino "hacerlos embajadores". De este modo, con la presencia de un solo desdoblamiento al inicio de texto se estaría dejando claro el posicionamiento inclusivo, pero con la premisa de no hacer ardua la lectura. 


\section{3·3. La forma -e}

Como ya se adelantó, el uso de la forma -e plantea una alternativa para dar cuenta de la diversidad de géneros y escapar del sistema binario -esto no aplica a los desdoblamientos o al uso de la barra, por ejemplo, que siguen la lógica binaria-. Por eso también se registra el uso en singular: "Estoy contente" o "Soy niñe". Tiene la ventaja, a diferencia del @y de la x, que puede usarse en la oralidad, pues posee una función fonológica que puede pronunciarse en castellano. Como lo ilustra el ejemplo (7), se plantea "el régimen de alumne embarazade" y la -e funciona claramente allí como una marca de reparo ante el género impuesto socialmente ${ }^{9}$. Si bien el uso de la -e en la Argentina se dio al principio en ciertos sectores sociales jóvenes, especialmente urbanos, se ha extendido a usos públicos, periodísticos y políticos.

(7) Fragmento de una nota

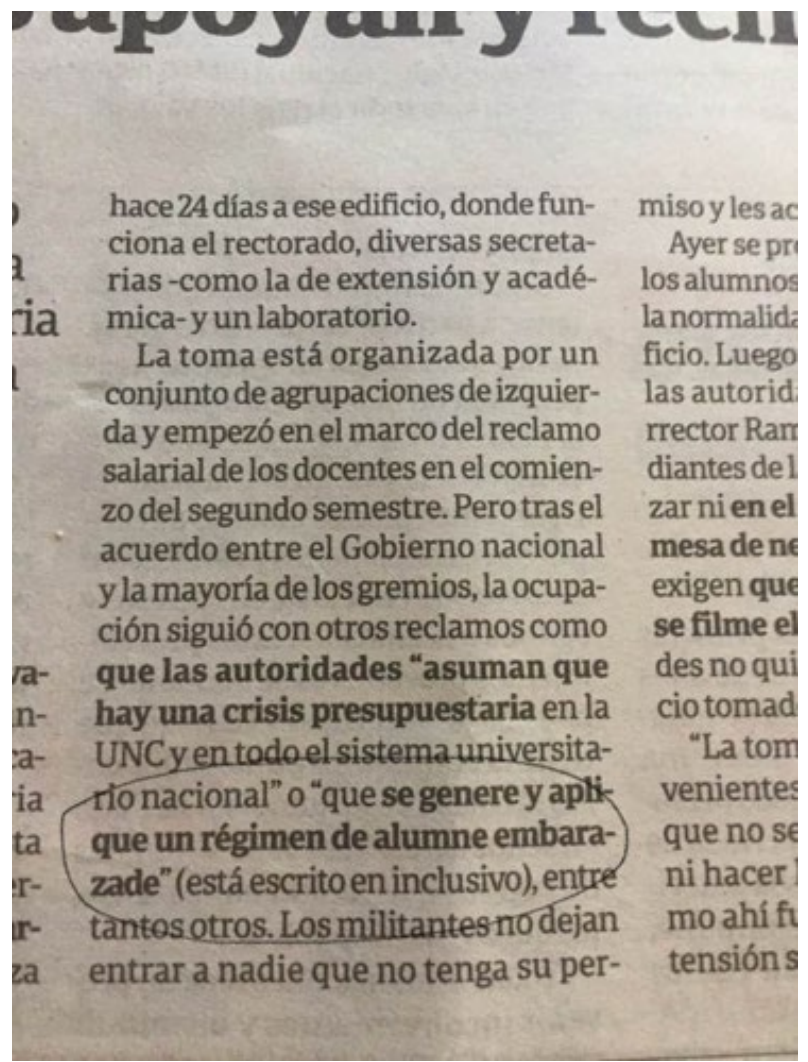

Como bien se sabe este uso conlleva substanciales transformaciones morfológicas. Al respecto, García Negroni cuestiona la factibilidad de su sistematización, porque "implica un cambio fuerte del sistema del español, que pasaría de un sistema morfológico con dos géneros (y un neutro en casos como esto, lo, etc.) a otro distinto en el que, por un lado, se mantendrían dos géneros (para los sustantivos y adjetivos que no remiten a

\footnotetext{
${ }^{9}$ En este caso, puede tratarse de una alumna cis emabarazada o un alumno trans y por ello "embarazade".
} 
seres humanos) y, por el otro, tendría un único género (terminado en -e) para sustantivos y adjetivos que remiten a seres humanos" (García Negroni, 20ı8: entrevista personal). De ahí que la sistematización de esta variante sea una incertidumbre y por ello muchos especialistas objetan su uso y no le auguran un buen futuro ${ }^{\mathrm{ro}}$. De todos modos, lo que hoy importa es que se trata de una configuración discursiva que exhibe aquellas identidades antes invisibilizadas. Aquí la necesidad de visibilización se impone sobre otros principios: de la economía y la "naturalidad" de la lengua.

Por otra parte, en (8) se reproduce un fragmento de una nota de opinión en el diario argentino Página 12, cuyo título es "La generación que les canta a les desaparecides”.

\title{
(8) La generación que les canta a les desaparecides
}

(...) La imagen más conmovedora de la marcha del domingo (para mí) la vi en un video publicado por este diario: un grupo de pibes y pibas, pero sobre todo pibas, de alrededor de quince años. Vienen por Avenida de Mayo cantando a los gritos y levantando las manos. No se escucha el principio pero dicen algo así: “...nuestro camino, marcado por las Madres y les compañeres desaparecides viven en nosotres porque no nos han vencido". Victoria Ginzberg en Diario Página 12, 26 de marzo de 2org. En:

https://www.paginar2.com.ar/I832I2-la-generacion-que-les-canta-a-les-desaparecides?fbclid $=$ IwAR2m6ZlHLiOMoKaU_VzVxhcWnoZyBNe2_GEncsYbSrBiqSCS_ngaLMfZC_F8

Allí vemos los cambios morfológicos que deben aplicarse al sintagma, sobre artículos, sustantivos, adjetivos y pronombres personales: "Les compañeres desaparecides viven en nosotres" (6). Si bien a mucha gente les puede parecer forzado y artificial este uso, es de destacar la fluidez y "naturalidad” con que los y las jóvenes construyen los sintagmas apelando al morfema $-e$.

Diversas posturas coinciden en que el lenguaje inclusivo constituye un fenómeno eminentemente político (Bentivegna, 20I8), en tanto implica una utilización política de la gramática (Menéndez, 20I8) y una práctica política, como explica aquí Andruetto:

\begin{abstract}
Algo que no existía comienza a ser nombrado, algo que ya existía quiere nombrarse de otro modo, verdadera revolución de la que no conocemos sus alcances, ni hasta dónde irá, ni si abarcará un día a la mayor parte de la sociedad, a sus diversas regiones, a las formas menos urbanas de nuestra lengua y a todos sus sectores sociales. No podemos prever su punto de llegada, pero sí sabemos que está entre nosotros de un modo tal que no podemos obviar. Lo que queda claro, lo insoslayable, es que se trata de una cuestión política, de que la lengua responde a la sociedad en la que vive, al momento histórico que transitan sus hablantes. (Discurso de clausura del Congreso Internacional de la Lengua Española, 30/3/2019).
\end{abstract}

\footnotetext{
Io En la explicación de García Negroni, queda claro que el uso de la -e se aplica solo a colectivos sociales; no se usa para referir a objetos o seres que no sean humanos.
} 
Teniendo en cuenta la dimensión política del lenguaje inclusivo, se puede sostener que sus recursos son marcas lingüísticas de disenso, en tanto funcionan como espacios de puesta en escena de la otredad genérica y emergen como huellas de la diversidad históricamente soslayada. Sin dudas, todas estas formas de lenguaje inclusivo generan efectos de sentido que nos interpelan como hablantes y por eso muchas veces nos incomodan y desestabilizan.

\section{El lenguaje inclusivo en el aula}

Desde 20I8, el lenguaje inclusivo (especialmente, con la marca -e) irrumpe en las aulas sin pedir permiso. Lo hablan/escriben alumnos y alumnas, lo hablan/escriben docentes, aparece en los discursos de circulación social.

¿Qué hacen las instituciones educativas y los y las docentes frente a este fenómeno? ¿Lo aceptan? ¿Lo cuestionan? ¿Lo desestiman en nombre de la gramática española?

En este apartado, trataré de hacer un breve recorrido por los aspectos más significativos que implica el abordaje de este tema en las aulas: I) la aceptación de su tratamiento/uso (o no); 2) su relevancia en la educación lingüística y la reflexión sobre el lenguaje; 3) su vinculación con la educación para la diversidad.

En primer lugar, comenzaré incorporando dos opiniones de alumnas del nivel secundario -adolescentes de I6 años-, que utilizan el lenguaje inclusivo en la escuela:

(9) Lo uso en el colegio todo el tiempo, ya sea en las clases o en los recreos con mis amigues y compañeres, porque la mayoría de elles también lo usan. Evito usarlo en ambientes donde las personas no lo usan o sé que no lo respetan. Los pronombres masculino y femenino ya no son suficientes, y es necesario ampliar nuestro lenguaje para no encontrarnos en la situación de estar dejando de lado a un grupo amplio de personas”. (Violeta Méndez, Ciudad de Buenos Aires).

(Io) Uso lenguaje inclusivo porque con el lenguaje hasta ahora no solo excluimos a las mujeres sino también a las personas de género no binario, y es muy importante hacer notar que existen y visibilizarles. Lo uso en entornos políticos, en la escuela con todes les profesores, en fiestas, etc. lo uso. Pero cuando me percibo en una situación vulnerable (por ejemplo, en un Uber con amigas, con adultes muy faches, etc.) o trato de buscar sinónimos de palabras que no tengan género y si es imposible no lo uso, aunque milito para que no sea así. (Manuela Carrera, Ciudad de Buenos Aires).

Ambos testimonios demuestran el uso frecuente y fluido del lenguaje inclusivo que manifiestan las hablantes, así como la puesta en juego de cuestiones gramaticales, y la reflexión sobre el lenguaje que ejecutan -por ejemplo, acerca de la función y efectos de sentido-. Asimismo, hacen hincapié en la carga ideológica del lenguaje, que habitualmente pasa inadvertida para los hablantes -adultos-. 
Desde esta perspectiva, es posible plantear que el abordaje sobre el lenguaje inclusivo permite reflexionar sobre las reglas, la normativa, la trasgresión, la homogeneidad, el prestigio lingüístico, el poder de las académicas. También se puede constituir como un tema propicio para encarar diferentes aristas de la educación lingüística ya que abarca variados conceptos y tópicos nodales, como la lengua, el lenguaje, el discurso, el género discursivo, la situación comunicativa, la formalidad/ informalidad, los principios de adecuación, cohesión y coherencia. Al respecto, Kalinowski sostiene que como herramienta pedagógica es muy útil, porque "primero, tenés a los alumnos motivadísimos con eso. Se dan las condiciones para hablar de formación de palabras, de raíz y vocal desinencial" (2OI9: 3). Además, se pueden establecer múltiples asociaciones con otras áreas. Por ejemplo, puede analizárselo en relación con los contenidos de ESI (Educación Sexual Integral), con la problemáticas sobre discriminación, de identidad de género, los géneros no binarios, etc.:

Cuando empezás a pensar cómo funciona la lengua, aparecen visibilizados un montón de nudos centrales de la ESI. Todavía no hay mucho material desarrollado sobre lenguaje no binario, pero en cuanto se piensa el problema aparece la ESI. No puede no aparecer. Esto sucede porque las categorías gramaticales pasan a discutirse en términos de organización del mundo. Yo creo que en cuanto aparece este tema en la escuela, los que estaban con el celular, hablando entre ellos o tirándose patadas por debajo del banco, se suman automáticamente a una discusión que los interpela. Es una vuelta de tuerca más en el dominio del lenguaje (Labeur, 20I9, 4).

No obstante y, como se puede suponer, indagar sobre el lenguaje inclusivo puede provocar múltiples tensiones. Por ejemplo, el año pasado un Ministerio de Educación provincial de la Argentina emitió una nota que desestimaba el lenguaje inclusivo como contenido curricular. A partir de diversos argumentos que tendían a mostrar que el lenguaje inclusivo "atentaba" contra el sistema de la lengua y era usado por un grupo minoritario, el Ministerio llegó a la siguiente conclusión:

(II) El Ministerio de Educación, si bien comprende que dicho lenguaje está presente dentro del contexto de ciertos grupos sociales, sostiene que no contempla su incorporación como eje temático para su abordaje dentro de las aulas de la provincia. (Nota 28 de 2018 del Ministerio de Educación de Corrientes. Nivel Secundario. El lenguaje inclusivo de los adolescentes. 8 de agosto de 20I8).

Pero, como ya se dijo, los usos lingüísticos no pueden prohibirse, aunque tampoco imponerse, es decir no porque se aborden en clase el alumnado los utilizará. Las instituciones educativas sin dudas tienen que estar abiertas a los debates actuales y fomentar una educación lingüística reflexiva que contemple la diversidad y la pluralidad. En efecto, 
ser la relativa al género o a la condición sexual, entre otras para elaborar propuestas de trabajo que ayuden a eliminar tales usos y, al mismo tiempo, a ser críticos con aquellos discursos presentes en todos los ámbitos de la vida cotidiana en los que, de una manera o de otra, se atenta contra la dignidad de otra (Quiles Cabrera 20I6: 9I).

En lo que sigue, presento dos ejemplos de circulación de lenguaje inclusivo en institutos terciarios del ámbito estatal, que intentan mostrar diferentes aristas del tema. En primer lugar, muestro una actividad propuesta en los Talleres de lectura, escritura y oralidad del Profesorado ISFD N 18 de Banfield (provincia de Buenos Aires), orientado a docentes en formación, a cargo de la profesora de Letras Aimé Esteban.
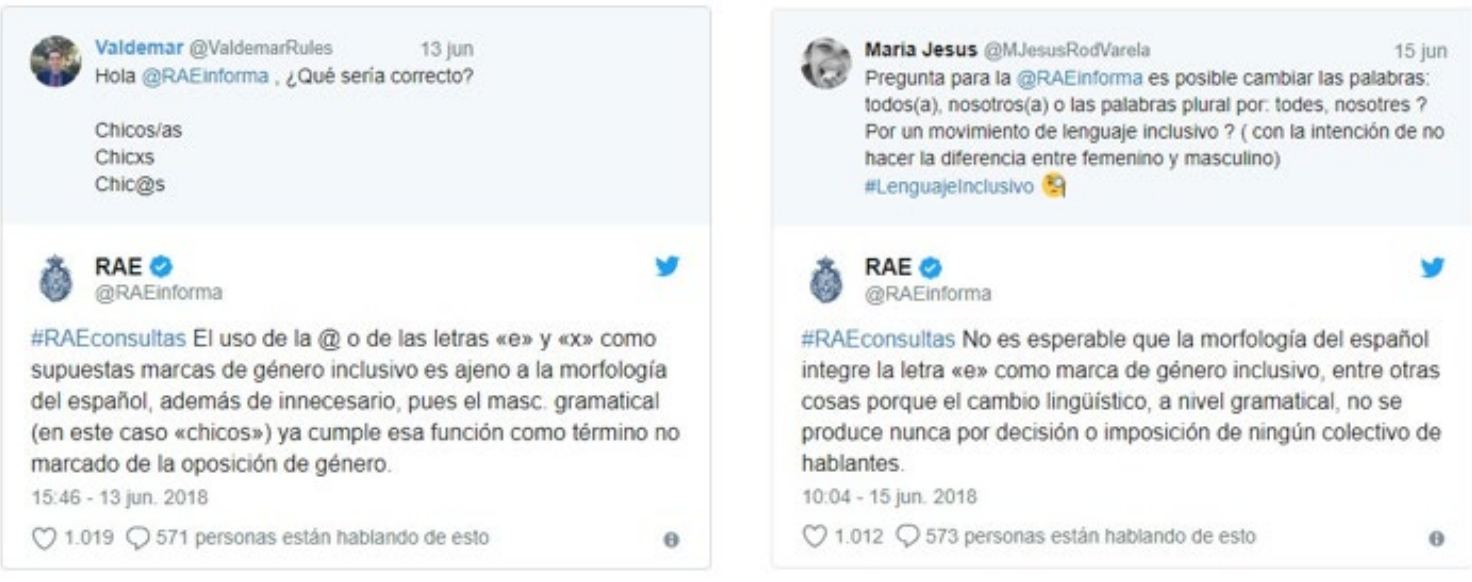

\section{Para conversar en pequeños grupos:}

I) ¿A qué género discursivo creen que pertenecen los textos? ¿Cuál es su ámbito de circulación social?

2) ¿Con quién/quiénes polemizan los textos? Justifiquen brevemente.

3) Enuncien la tesis de la RAEy un argumento que la institución dé para sostenerla.

4) ¿Qué trama creen que predomina en el discurso de la RAE? ¿Expositiva y/o argumentativa? Justifiquen.

5) Señalen dos palabras que funcionen devaluando o ridiculizando a quienes tienen una posición diferente. ¿Les parecen necesarias?

Como observamos, la docente eligió tuits de consultas de usuarios a la RAE, que constituyen textos de debate sobre lenguaje inclusivo. Luego de la resolución de las consignas, centradas en el contenido curricular -el abordaje de la secuencia argumentativa-, la docente comenta que se produjo un interesante debate sobre lenguaje inclusivo. De este modo, se registran como estrategias didácticas la lectura, y el análisis de textos sobre 
lenguaje inclusivo, para tratar un contenido disciplinar específico, que luego motivó la reflexión y la discusión sobre el tema.

En segundo lugar, me referiré a la escritura de textos en lenguaje inclusivo por parte de estudiantes. A modo de ejemplo, presento un fragmento de la planificación redactada por dos alumnas (Marina De Biase y Carla Giraud) del Profesorado de Educación Primaria de la Escuela Normal Superior $\mathrm{N}^{\circ} 4$ del barrio Caballito (Ciudad de Buenos Aires), cuya práctica se realizó en una escuela de tercer grado de la Ciudad de Buenos Aires.

$(\mathrm{I} 3)$

\section{Planes de clases de Conocimiento del mundo Vivir en la Ciudad de Buenos Aires: lugares emblemáticos}

(...) A través del estudio de los diferentes lugares emblemáticos que hemos seleccionado de la CABA, nos proponemos que les alumnes relacionen el pasado y el presente de la ciudad en la que viven y la manera en la que ésta se configuró de acuerdo a las diferentes condiciones particulares bajo las cuales ocurrieron las acciones, los procesos sociales y les diferentes actores sociales en ellos. Ofreceremos a les niñes distintas fuentes de análisis de diferentes soportes para generar un ambiente en el que surjan preguntas y respuestas que posibiliten la integración de los conocimientos abordados.

Así mismo, les niñes aprenderán de la ciudad y sobre la ciudad de acuerdo con los distintos enfoques que plantean Alderequi y Villa: morfológico, histórico patrimonial, social y ciudadanía (Paidós, I998, p.IOI-I27) para que, a través de su estudio, les alumnes comprendan cambios y permanencias, intencionalidad y contextualización. (...)

Marina De Biase, una de las estudiantes que diseñó dicha planificación, justifica de este modo la redacción (ejemplos: "les alumnes" y "les niñes”):

Intento incorporar el lenguaje inclusivo en mi práctica ya que el mismo permite el reconocimiento de diversas identidades de género que existen y el patriarcado históricamente silenció. Es una tarea difícil pero que de la que vamos aprendiendo. El lenguaje es un campo de batalla y de resistencia. Como garante de derechos e igualdad ¿cómo no seguir peleando por la igualdad desde allí también? (20I9, entrevista personal).

Por su parte, Osvaldo Osorio, el docente a cargo de las prácticas docentes de las alumnas, sostiene que acepta textos escritos en lenguaje inclusivo en sus materias por- 
que él lo usa en el discurso oral y escrito desde hace más de io años, especialmente la doble mención y barras. Explica que su posición excede la moda, puesto que es una posición teórica e ideológica.

Estos casos muestran de modo categórico la dimensión política del lenguaje inclusivo y cómo incide en la construcción de las subjetividades pedagógicas y en la construcción de las identidades docentes. Sin dudas, atraviesa las prácticas y funciona como herramienta de lucha y de reivindicación de las identidades de género. No se puede soslayar su presencia, su relevancia y los efectos de sentido que produce.

Hay quienes les puede parecer un sinsentido aplicar el lenguaje inclusivo o que lo cuestionen por considerar su uso una mera corrección política, pero de eso también hay que hablar y debatir en el aula. Lo fundamental es contraponer las diferentes posturas y participar del debate.

Por otra parte, es preciso pensar dentro de las instituciones educativas la relación entre lenguaje inclusivo y discapacidad. De acuerdo con Verónica Suckazer, escritora y periodista, hay que tener en cuenta que si la palabra escrita no tiene correlación fonética (como el @ o lax) no coincide con el diccionario mental del sujeto y, por ende, no puede ser leída por diversos grupos o lectores electrónicos. Para las personas no videntes son obstáculos de lectura y para aquellas con discapacidad auditiva son obstáculos de comprensión oral y escrita en muchos otros casos. Como sugiere Suckazer:

Hay que estudiar seriamente qué sucede, por un lado, con los lectores que utilizan las personas ciegas para leer, si pueden leer este "lenguaje inclusivo". Y, por el otro, indagar los mecanismos de la lectura labial en las personas sordas, más la relación entre sordera y capacidad lingüística, así como estar atento a las dificultades de personas con dislexia y demás trastornos del aprendizaje (20I9, entrevista personal).

Para finalizar, aclaro que en este apartado busqué mostrar que en la actualidad la educación lingüística no puede obviar las diferentes tendencias en los usos ni excluirlos del aula. Tampoco la cuestión es que se inste a que se hable "en inclusivo"; como bien sabemos no se pueden imponer modos de hablar -para que un cambio se instale y se sistematice deben pasar muchos años, incluso varias décadas-, pero tampoco prohibirlos o silenciarlos. En suma, debatir sobre los usos del lenguaje implica hablar sobre la sociedad, sobre sus problemas, exclusiones y olvidos. 


\section{A modo de cierre}

En el presente artículo quise demostrar que las formas de lenguaje inclusivo pueden entenderse, por un lado, como marcas lingüísticas que evidencian la diversidad históricamente soslayada, pues ponen escena las identidades genéricas invisibilizadas. Por otro lado, emergen como huellas de disenso ante el paradigma patriarcal y binarismo, ya que través de algunos recursos como lax, el @y el morfema-e, se reconocen y visibilizan los paradigmas e identidades que discuten el sistema binarista. Todas estas formas de lenguaje inclusivo cimentan una postura política (Andruetto, 20I9) y de militancia teórica y generan efectos de sentido que, al cuestionar los usos convencionales, pueden incomodarnos como hablantes y desestabilizar los discursos. Si bien en la Argentina el lenguaje inclusivo fue al principio utilizado por determinados grupos urbanos, en general jóvenes, hoy fluye en diferentes esferas sociales, atraviesa las prácticas discursivas y nos interpela como hablantes.

Finalmente, planteé el tratamiento del lenguaje inclusivo en el ámbito educativo y su relevancia como objeto de discusión para una educación lingüística que fomente la diversidad, la pluralidad y el pensamiento crítico.

En suma, el lenguaje inclusivo pone en juego cuestiones relacionadas con las identidades, la ideología, las normas, la corrección y el poder. Su tratamiento en las clases implica pensar todos estos aspectos y abrir espacios de reflexión y debate. 


\section{Bibliografía}

-Alario, C., Bengoechea, M., Llendó E. y Vargas, A. (1995). La representación de lo femenino y lo masculino en la lengua. Madrid: Instituto de la Mujer.

- Andruetto, M. T. (20I9). Discurso de cierre del Congreso de la Lengua. Córdoba: 30/o3/20I8. Obtenido el o3 de abril de 2019 desde https://www.lavoz.com.ar/numerocero/completo-magistral-discurso-de-maria-teresa-andruetto-para-cierre-del-congresode-lengua

- Bentivegna, D. (2018). Lenguaje inclusivo. La expansión de lo político. Charla-debate, Buenos Aires, 23 de noviembre de 2018.

- Bosque, I. (2012). Sexismo lingüístico y visibilidad de la mujer. En Plenaria de la Real Academia Española. Madrid: I7/o3/20I2. Obtenido el Io de abril de 2019 desde http://www. rae.es/sites/default/files/Sexismo_linguistico_y_visibilidad_de_la_mujer_o.pdf

- Butler, J. (1990). El género en disputa. El feminismo y la subversión de la identidad. Barcelona: Paidós.

- Kalinowski, S. (2019). Es una herramienta pedagógica fantástica. La educación en debate \#68. Unipe, marzo de 2org. (p. 3).

- Labeur, P. (20I9). Sirve para instalar la ESI. La educación en debate \#68. Unipe, marzo de 2OI9. (p. 4).

- Martos, E. y Campos, M. La lectura y la escritura en el siglo XXI: Cultura letrada y modernidad. Álabe 5, junio 20I2. Obtenido el I4 de mayo desde: http://revistaalabe.com/index/ alabe/article/view/ı32

- Menéndez, M. (20I8). Idioma y política. Lenguaje para todes. Diario Perfil, iz de agosto, de 20I8. Obtenido el 30 de marzo de 20I9 desde https://noticias.perfil.com/20I8/o8/I7/ idioma-y-politica-lenguaje-para-todes/

- Orlandi, E. P. [2003] (2009). A Linguagem e seu funcionamento. As formas do discurso. Campinas: Pontes.

- Pêcheux, M. (1975) . (1975) [1988]. Semántica e Discurso. Uma Crítica a Afirmacao do Obvio. Trad. Eni P. de Orlandi et al. Campinas: Editora de UNICAMP.

-______(1983). O discurso: Estructura ou Acontecimiento, Trad. Eni P. de Orlando. Campinas: Pontes. 
- Quiles Cabrera, M. (2OI6). Didáctica del discurso en la escuela diversa: aprender lengua para la convivencia. En Martínez Ezquerro, A. y Campos Fernandez- Fígares, M. (eds.) Cultura en la diversidad. Educación lingüistica y literaria en las aulas del siglo XXI. Barcelona: Octaedro.

- Ramírez Gelbes, S. (20I9). Sobre lenguaje inclusivo. Les invito a todes. Noveduc.com. Obtenido el I4 de mayo desde: https://www.noveduc.com/noticia/I297

- Tosi, C. (20I8). Nuestro idioma en el banquillo por machista. Revista $\tilde{N}, 7 / 9 / 2018$. (pp. 7-IO).

-Zabala, F. (20I8). “Les lingüistas y la inclusión”. Recuperado de: http://www.catedracosgaya.com.ar/tipoblog/20r8/les-linguistas-y-la-inclusion/ 